DOI: $10.14451 / 1.193 .207$

\title{
ЦИФРОВЫЕ ТЕХНОЛОГИИ В ОБЕСПЕЧЕНИИ РАЗВИТИЯ ЭКОНОМИКИ
}

\author{
(C) 2020 Головинов Петр Николаевич \\ кандидат экономических наук, \\ соискатель кафедры экономики и управления предприятиями и производственными комплексами \\ Санкт-Петербургский государственный экономический университет, Россия, Санкт-Петербург \\ E-mail: p.golovinov@gmail.com \\ (c) 2020 Смирнов Владимир Владимирович \\ магистрант 2-го года обучения \\ кафедры экономики и управления предприятиями и производственными комплексами \\ Санкт-Петербургский государственный экономический университет, Россия, Санкт-Петербург \\ E-mail: bekon1234567@mail.ru
}

В статье рассматриваются вопросы обеспечения развития российской экономики на основе цифровых технологий. Показаны роль и место информационно-коммуникационных технологий в развитии энергетических отраслей экономики.

Ключевые слова: цифровые технологии, энергетика, цифровизация, цифровая безопасность

Формирование экономики, базирующейся на цифровых технологиях имманентно общему развитию и представляет собой экономику, существующую в так называемом «гибридном» мире. Последний же выступает как результат слияния реального мира с виртуальным, когда все действия реального мира возможны, в том числе, через виртуальный, хотя и ограничены определенными условиями (высокая эффективность и сравнительно низкая стоимость ИКТ и «всенародная» доступность цифровой инфраструктуры). Указ Президента РФ от 9 мая 2017 г. № 203 «О Стратегии развития информационного общества в Российской Федерации на 20172030 годы» определяет цифровую экономику как «хозяйственную деятельность, в которой ключевым фактором производства являются данные в цифровом виде, обработка больших объемов и использование результатов анализа которых по сравнению с традиционными формами хозяйствования позволяют существенно повысить эффективность различных видов производства, технологий, оборудования, хранения, продажи, доставки товаров и услуг» [1].

В рамках взаимодействия в цифровой экономике, предполагается, что субъектам и объектам процесса присуща значительная цифровая составляющая (например, программное обеспечение автомобиля и датчики, стоимость которых в совокупности составляет более половины стоимости всего автомобиля), благодаря чему улучшаются основные потребительские свойства, в том числе, безопасность, а также формируются новые свойства (например, управление мобильным телефоном или автомобилем с помощью голоса, а в будущем и взглядом).

Таким образом, можно сформулировать более, на наш взгляд, корректное определение цифровой экономики как экономики, характеризующейся максимально возможным удовлетворением потребностей всех ее участников за счет использования информации, в том числе и персональной, реализуемым с применением ИКТ, технологий, цифровой инфраструктуры, что формирует возможность обеспечить полноценное взаимодействие всех активных участников экономической деятельности в сформированном гибридном мире.

Можно выделить следующие пять отличительных черт экономики, построенной на основе цифровых технологий [2] (рис.1):

- все взаимодействия субъектов экономики осуществляются в цифровой среде (программном комплексе), удовлетворяющем потребности производителей и потребителей в прямом взаимодействии;

- модели, ориентированные на конкретные интересы каждого клиента, в частности, технологии Big Data, таргетированный маркетинг, 3D печать;

- прямое взаимодействие (см. выше) производителей и потребителей, которое обеспечивается благодаря развитию ИКТ за счет сокращения цепочек посредников; [3]. 


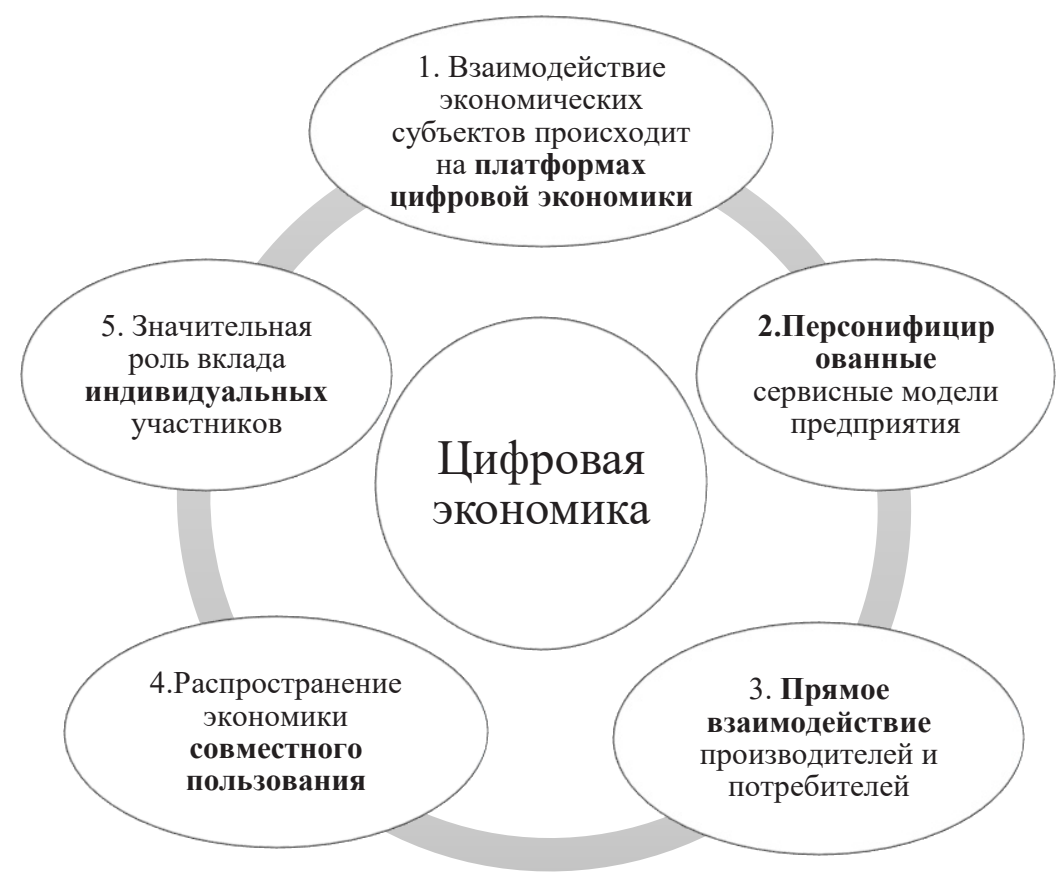

Puc. 1. Отличительные черты экономики, построенной на основе цифровых технологий

- распространение экономики совместного пользования; растет значимость вклада каждого человека в экономику, поскольку развитие технологий позволяет усилить их роль в существующих бизнес-процессах, а также реализовывать новые виды бизнес-процессов.

Если говорить о подходах к построению экономики на основе цифровых технологий, можно выделить плановый и рыночный подходы, что коррелируется с плановой и рыночной экономиками [4].

Рыночный подход к построению цифровой экономики предполагает, что создание государством благоприятной среды развития цифровой экономики, что, в свою очередь, стимулирует бизнес-структуры к переходу в новый сектор экономики. Оптимизация условий цифровизации экономики предполагает наличие или, хотя бы планирование, комплекса взаимосвязанных мер социального, экономического, экологического характера, а также соответствующей технико- технологической базы. Сверх этого, должно быть реализовано условие наличия большого количества независимых субъектов экономики в частном секторе, поскольку величина положительного эффекта цифровизации экономики, как и других экономических явлений, зависит от масштаба.

Плановый поход к построению цифровой экономики предполагает развитие и постоянное совершенствование инфраструктуры, технологий под государственным патронажем и целенаправленное насыщение соответствующего сектора (сегмента) экономики хозяйствующими субъектами. Т.е. одновременно формируются и технологический базис, и среда, условия которой благоприятны развитию частного бизнеса. Сами же технологический базис и инфраструктура выбираются и развиваются в соответствии с приоритетными направлениями плановой цифровой экономики. Преимуществом планового подхода представляется более высокая по сравнению рыночной скорость формирования и развития цифровой экономики. Тем не менее, в реальности все цифровые стратегии представляют собой сочетание этих двух подходов.

Представим основные технологии, обеспечивающие развитие экономики на цифровой основе или Индустрии 4.0 - четвертой индустриальной революции, в результате которой происходит переход на полностью цифровое производство, с управляющими интеллектуальными системами, реализуемое в режиме реального времени, практически преодолевающее границы одного предприятия и представляющее собой, с перспективой объединения, глобальную промышленную сеть (рис. 2).

Цифровизация экономики направлена на 


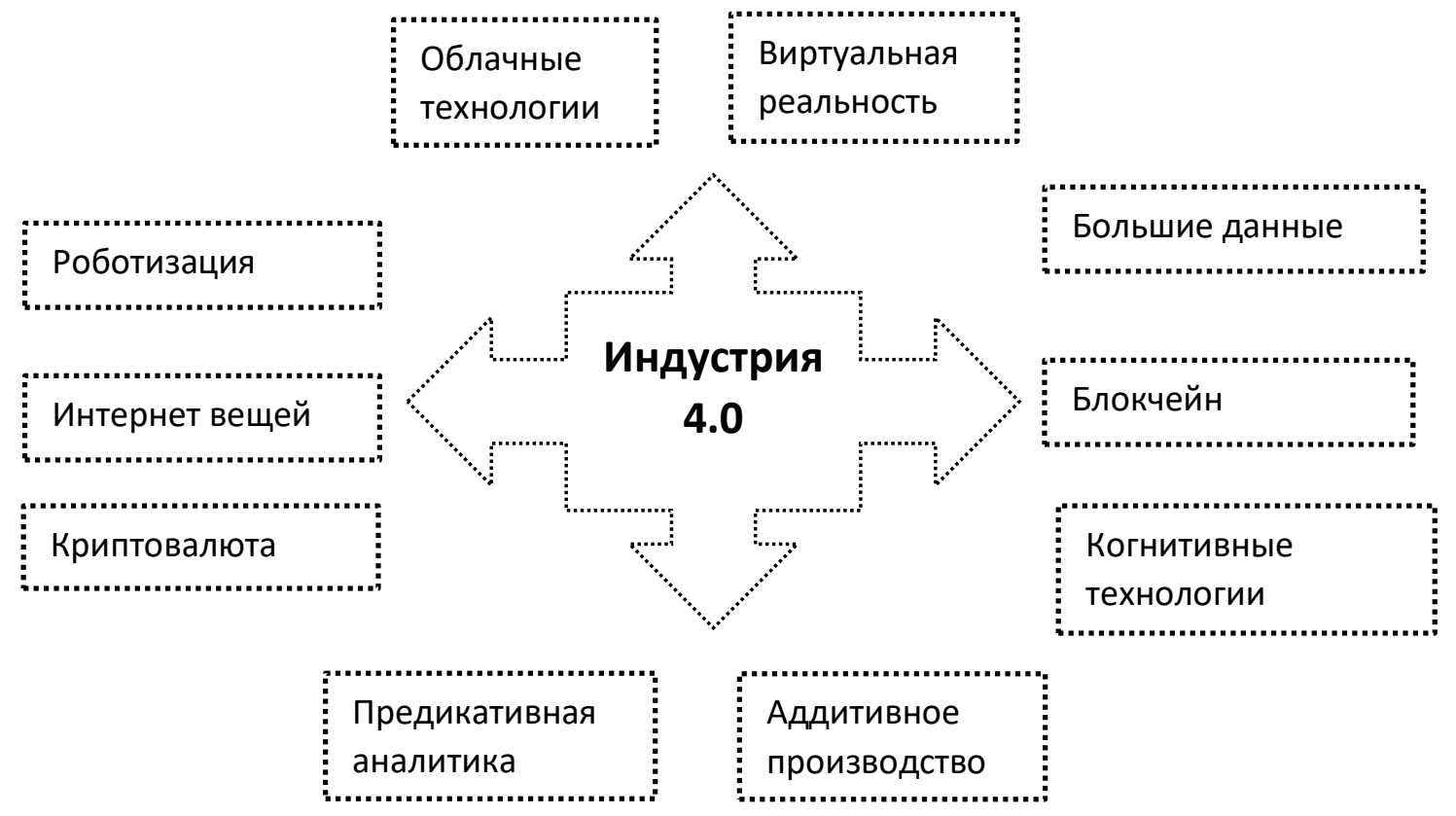

Puc. 2. Технологии в цифровой экономике [5]

извлечение большей выгоды (прибыли, получения эффекта) при изменении принципа взаимодействия бизнес-процесса любой коммерческой компании. Если говорить об энергетике, цифровизация позволит применить новые технологии как в сфере генерации, так и в последующей передаче и обработке полученной энергии или топлива посредникам и конечным потребителям. В конечном итоге применение цифровизации должно привести к снижению производственных и логистических издержек. Главные бизнес-процессы, где можно достичь результата, находятся на этапе генерации энергетических ресурсов, далее их обработке и на конечном этапе отправки их потребителям.

Как известно, основной целью цифровой экономики является рост качества жизни, рост уровня конкурентоспособности государства и обеспечение безопасности всех объектов от физической безопасности населения до экономическое и военной безопасности государства. Как позитивный фактор, можно отметить, что, благодаря цифровизации экономики происходит исчезновение старых и возникновение новых профессий, что требует от общества ускоренной адаптации к происходящим изменениям. Только страны, активно использующие (институциональные потребители и физические лица) цифровые инструменты могут обеспечить ускоренный рост экономики. Социальная среда граждан также не остается в стороне. Это и телемедицина, дистанционное обучение и повышение квалификации, быстрый доступ к государственным услугам, «Умные города», «Умные системы движения - все повышает качество жизни и безопасность граждан, а, следовательно, и имидж государства.

Энергетика представляет собой достаточно широкую сферу деятельности, охватывающую ряд отраслей и видов производства, широкий спектр бизнес-процессов, что делает многосторонним использование цифровых технологий. Следует отметить, что соответствующие технологии уже достаточно давно нашли применение в энергетике, хотя результаты не всегда можно считать позитивными. В частности, уже во втором десятилетии двадцать первого века интенсивно использовались такие базовые технологические ресурсы цифровизации, как: облачные средства коммуникации и хранения информации; Smart-технологии; PLM и САПР и ряд других.

Следует отметить, что предприятия энергетики неоднородны по уровню автоматизации, так сетевые компании преуспели в этом отношении, у генерирующих компаний фактический уровень автоматизации может быть ниже, хотя необходимо рассматривать конкретную ситуа- 
цию, как и в случае сбытовых компаний. Энергетические компании, впрочем, как и все остальные, глубоко заинтересованы в безопасности данных, что приводит к определенной осторожности при выборе и внедрении облачных технологий.

Для энергетики, как и для многих других отраслей экономики и промышленности наиболее актуальны технологии, обеспечивающие рост производительности труда, надежность и непрерывность функционирования энергетических систем. Как известно, одной из проблем российской энергетики является старение основных фондов (технологического оборудования) и ухудшение технического их состояния. Так, в 2019 году износ основных фондов в экономике составил примерно 47,6\% [6]. В энергетике износ основных фондов несколько меньше, хотя значимость их поддержания в рабочем состоянии значительно выше, поскольку они относятся к отраслям жизнеобеспечения.

Соответственно российские энергетические компании должны уделять внимание не только процессу своевременной замены оборудования, но и технического обслуживания и ремонта (текущего и капитального) оборудования, а оптимизация затрат на эти ремонты будет основана на оценке состояния оборудования, использовании методик оценки вероятности и последствий отказа оборудования. Таким образом, реализуется возможность эффективного управления техническими и экономическими ресурсами в целях уменьшения операционных и капитальных затрат на основе автоматизации поддерживающих процессов с помощью цифровых технологий.

Основным инструментом для ускоренного эффективного организационно-технического развития становятся высокие технологии, однако их использование диктует обеспечение дополнительных условий: наличие современного оборудования, позволяющего производить его цифровизацию и высокотехнологичного персонала, владеющего всеми знаниями и навыками обеспечения инновационных процессов. Растущий интерес к технологиям «Индустрии 4.0» увеличивается в геометрической прогрессии, так же, как и спрос на продукцию энергетических отраслей. Соответственно, для этих предприятий приоритетами становится совершенствование технологических процессов, способствующих производству продукции, отвечающей требованиям рынка.

\section{Библиографический список}

1. Комаров А.В., Борисова Е. С., Кузбенова Э. Р. Прогнозирование экономического развития России до 2025 года в условиях становления цифровой экономики//Эономика и предпринимательство, № 3 (92), 2018. С.88-97

2. Лаврентьева Л.В., Ящкова Е.В. Значение национальной «цифровой экономики» в общественной и финансовой жизни//Инновационная экономика: перспективы развития и совершенствование. № 1 (27). 2018.С.98103.

3. Зиркаев Р. С. Перспективы внедрения цифровой экономики в промышленность//Вестник Московского городского педагогического университета. серия: экономика, № 3(17), 2018. С.8-13

4. Пискунова О.В. Роль цифровых технологий в развитии экономики XXI века: плановый и рыночный подходы. В сб.: Перспективы социально-экономического развития в ХХІ столетии: инновационные, финансовые, информационные и правовые аспекты. Сборник научных трудов Международной научно-практической конференции. Под редакцией В.Н.Немцева, А. Г. Васильевой. 2019

5. Цифровизация: история, перспективы, цифровые экономики России и мира - Управление производством (up-pro.ru)

6. Основные фонды Росстат: стоимость, коэффициент, динамика (rosinfostat.ru) 